\title{
CORRESPONDENCE
}

\section{SIR WILLIAM READ'S TREATISE}

\section{To the Editors of The British Journal of Ophthalmology.}

SiRs,-The great interest of Mr. Sorsby's paper on Sir William Read's Treatise prompts me to mention that there is a copy in the St. Thomas's Hospital Library.

Its presence brought me discomfiture and the Regius Professor at Cambridge, I think, amusement, for, in a historical note on Phlyctenular Ophthalmia for my M.B. thesis in 1926, I ingenuously gave Sir William as a reference, mentioning that he had added nothing to Banister's description of a century earlier.

$$
\text { I am, yours faithfully, }
$$

Howard Coverdale.

AuCKLaND,

N.Z.

NOTES

French Cours de perfectionuement in Ophthalmic Surgery
Professor TerRIEN announces the customary post-graduate course in ophthalmic surgery to be held at the Hôtel Dieu, Paris, during the last ten days in October, 1932. The course begins on October 21, and consists of lectures and practical work. A visit to the Institute of Radium will be included. A certificate will be issued to each student at the end of the course and the fee has been fixed at 300 francs. Further information can be obtained from Professor Terrien.

Library

Tне Memorial Ophthalmic Laboratory, Giza, Requirements Egypt, sends us the following list of Journals and Periodicals required to complete sets :-

Transactions of the Ophthalmological Society of the U.K., Vol. XLV, 1925.

Royal London Ophthalmic Hospital Reports, Vols. XI-XIV.

Ophthalmic Review, Vols. I-XXX.

Ophthalmology, Vols. VIII, IX.

Transactions of the Amer. Ophthal. Society, 1864, 1865, 1867, 1868, 1871, 1872, 1884, 1895, 1896, 1900, 1914, 1918, 1919. 